\title{
Conformational Study of $\alpha$ Poly(L-valine). A Vibrational Approach
}

\author{
Leena Burman, Poonam Tandon, V. D. Gupta, ${ }^{\dagger}$ and S. Rastogi
}

Physics Department, Lucknow University, Lucknow 226 007, India

(Received July 24, 1995)

\begin{abstract}
In continuation to our work on the oligomapping of the dispersion curves of poly( $\mathrm{L}$-valine) in $\beta$ form, the present work is a study of normal modes and their dispersion in the $\alpha$ form. The Urey Bradley force field used in Wilson's GF matrix method has been transferred from the $\beta$ form and refitted to explain the FTIR spectra. The characteristic features of the dispersion curves involve repulsion with character exchange and tendency of certain pair of modes involving the motion of $\mathrm{C}_{\alpha}$ atom to come closer near the helix angle. Predictive value of heat capacity is obtained from the density-of-states. It is observed that the mixed modes make the maximum contribution.
\end{abstract}

KEY WORDS Conformation / $\alpha$ Helix / Crossing Over / Density-of-States /

In an earlier publication, ${ }^{1}$ the authors have reported a study of the normal vibrations, their dispersion and oligomapping of the dispersion curves of poly(L-valine) in the $\beta$ form. In continuation of this work, we report in the present communication a study of phonon dispersion in the $\alpha$ form of this biopolymer. Predictive values of heat capacities calculated from the density of states are also presented. To the best of our knowledge no such studies have been reported so far for $\alpha$ poly(L-valine).

Contrary to the earlier conclusions from calculations and experiments that poly(L-valine) (PLV) did not exist in $\alpha$-helical form, ${ }^{2-5}$ Scheraga and others ${ }^{6}$ on the basis of conformational mapping predicted the existence of Poly(L-valine) in right handed $\alpha$-helical conformation. Experimental studies on block copolymers of L-valine and $\mathrm{D}, \mathrm{L}-\mathrm{lysine}$ in solution by Epand et al. $^{7}$ confirmed this theoretical prediction. High molecular weight PLV can be prepared by polymerizing the $N$-carboxyanhydride of L-valine in anisole. ${ }^{8}$ Raman spectroscopic studies ${ }^{9}$ on polymers of L-valine for the degree of polymerization $(D P)$ greater than 500 , also indicated the existence of PLV in $\alpha$ helical form, although $\alpha$ helical content is not directly proportional to $D P$. The existence of right handed $\alpha$ PLV (Figure 1) could be attributed to the rotation about the $\mathrm{C}_{\alpha}-\mathrm{C}_{\beta}$ bond $\left(\chi_{1}\right)$. The set of $\chi$ 's is an important variable in deciding the minimum energy configuration that the polymer adopts. The rotation around the $\mathrm{C}_{\alpha}-\mathrm{C}_{\beta}$ bond moves the bulky side groups (methyl groups) away from the amide groups and thus it relieves the steric hinderance being caused by the proximity of the side-chain and main-chain groups. Earlier non-bonded interactions are now gradually replaced by new ones. This facilitates the formation of $\alpha$ helix.

\section{THEORY}

Normal mode analysis of $\alpha$ PLV has been performed according to Wilson's GF matrix method ${ }^{10}$ as modified by Higgs ${ }^{11}$ for an infinite chain. Details about his calculation have been discussed in the paper on phonon dispersion in $\beta$ poly(L-valine). ${ }^{1}$ The spectra of high molecular weight poly(L-valine) in the $4000-200 \mathrm{~cm}^{-1}$ fre-

$\dagger$ To whom all correspondence should be addressed. quency range was obtained from Prof. Takuya Yamashita (Faculty of Pharmaceutical Sciences, Tokushima University, Japan). The calculated frequencies at $\delta=0$ and $\delta=5 \pi / 9$ are compared with the observed infrared and Raman frequencies. The final force constants are shown in Table I. The dispersion curves below $1300 \mathrm{~cm}^{-1}$ are shown in Figures 2(a) and 3(a).

One of the important uses of dispersion curves is to calculate specific heat of a polymeric system. For a one dimensional system the density-of-state function or the frequency distribution function, which expresses the way energy is partitioned among the various branches of normal modes in the crystal, is calculated from the relation

$$
g(v)=\left.\sum_{j}\left(\partial v_{j} / \partial \delta\right)^{-1}\right|_{v_{j}(\delta)=v}
$$

The sum is over branches $j$. Considering a solid as an assembly of harmonic oscillators, the frequency distribution $g(v)$ is equivalent to a partition function. It can be used to compute thermodynamic quantities such as free

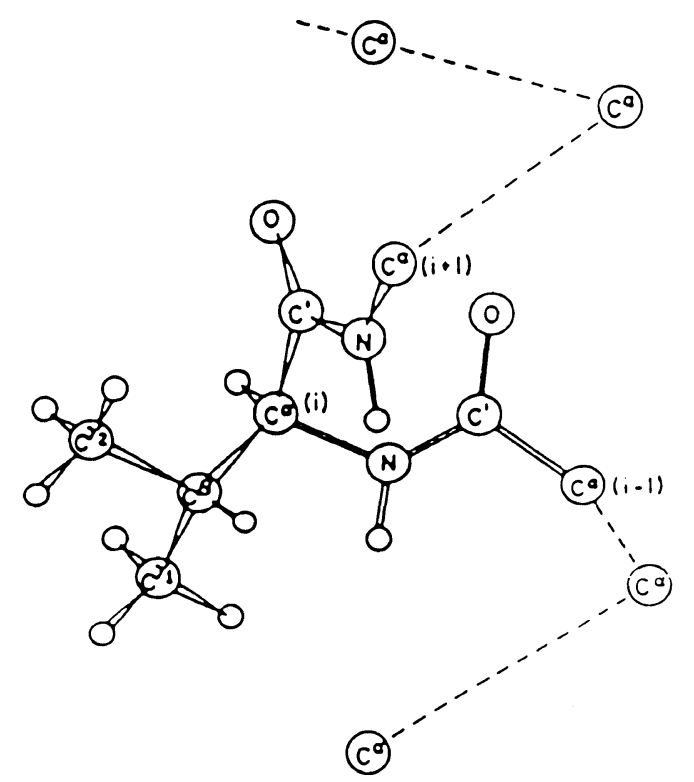

Figure 1. Side-chain and backbone conformation for the right handed $\alpha$ helix of poly(L-valine). 
Table I. Internal coordinates and force constants $\left(\mathrm{md} \AA^{-1}\right)^{\mathrm{a}}$

\begin{tabular}{llll}
\hline$v(\mathrm{C}==\mathrm{N})$ & 5.570 & $\phi\left(\mathrm{O}==\mathrm{C}-\mathrm{C}_{\alpha}\right)$ & $0.080(0.60)$ \\
$v\left(\mathrm{C}_{\alpha}-\mathrm{N}\right)$ & 3.250 & $\phi(\mathrm{O}==\mathrm{C}==\mathrm{N})$ & $0.170(0.90)$ \\
$v\left(\mathrm{C}_{\alpha}-\mathrm{C}_{\beta}\right)$ & 2.500 & $\phi\left(\mathrm{C}_{\alpha}-\mathrm{C}==\mathrm{N}\right)$ & $0.140(0.60)$ \\
$v\left(\mathrm{C}_{\beta}-\mathrm{C}_{\gamma 1}\right)$ & 2.200 & $\phi\left(\mathrm{C}_{\gamma 1}-\mathrm{C}_{\beta}-\mathrm{C}_{\gamma 2}\right)$ & $0.340(0.20)$ \\
$v\left(\mathrm{C}_{\beta}-\mathrm{C}_{\gamma 2}\right)$ & 2.200 & $\phi\left(\mathrm{C}_{\gamma 1}-\mathrm{C}_{\beta}-\mathrm{H}_{\beta}\right)$ & $0.515(0.22)$ \\
$v(\mathrm{H}-\mathrm{N})$ & 5.390 & $\phi\left(\mathrm{C}_{\gamma 2}-\mathrm{C}_{\beta}-\mathrm{C}_{\beta}\right)$ & $0.515(0.22)$ \\
$v\left(\mathrm{H}_{\alpha}-\mathrm{C}_{\alpha}\right)$ & 4.140 & $\phi\left(\mathrm{H}_{\beta}-\mathrm{C}_{\beta}-\mathrm{C}_{\alpha}\right)$ & $0.500(0.22)$ \\
$v\left(\mathrm{H}_{\beta}-\mathrm{C}_{\beta}\right)$ & 4.440 & $\phi\left(\mathrm{C}_{\beta}-\mathrm{C}_{\gamma 1}-\mathrm{H}_{\gamma}\right)$ & $0.440(0.22)$ \\
$v\left(\mathrm{H}_{\gamma}-\mathrm{C}_{\gamma 1}\right)$ & 4.290 & $\phi\left(\mathrm{C}_{\beta}-\mathrm{C}_{\gamma 2}-\mathrm{H}_{\gamma}\right)$ & $0.440(0.22)$ \\
$v\left(\mathrm{H}_{\gamma}-\mathrm{C}_{\gamma 2}\right)$ & 4.290 & $\phi\left(\mathrm{H}_{\gamma}-\mathrm{C}_{\gamma 1}-\mathrm{H}_{\gamma}\right)$ & $0.425(0.24)$ \\
$v\left(\mathrm{C}_{\alpha}-\mathrm{C}\right)$ & 2.300 & $\phi\left(\mathrm{H}_{\gamma}-\mathrm{C}_{\gamma 2}-\mathrm{H}_{\gamma}\right)$ & $0.425(0.24)$ \\
$v(\mathrm{C}==\mathrm{O})$ & 8.580 & $\phi\left(\mathrm{C}_{\gamma 1}-\mathrm{C}_{\beta}-\mathrm{C}_{\alpha}\right)$ & $0.210(0.20)$ \\
& & $\phi\left(\mathrm{C}_{\gamma 2}-\mathrm{C}_{\beta}-\mathrm{C}_{\alpha}\right)$ & $0.210(0.20)$ \\
$\phi(\mathrm{H}-\mathrm{N}==\mathrm{C})$ & $0.355(0.60)$ & $\omega(\mathrm{N}-\mathrm{H})$ & 0.120 \\
$\phi\left(\mathrm{H}-\mathrm{N}-\mathrm{C}_{\alpha}\right)$ & $0.345(0.50)$ & $\omega(\mathrm{C}==\mathrm{O})$ & 0.480 \\
$\phi\left(\mathrm{C}=-\mathrm{N}-\mathrm{C}_{\alpha}\right)$ & $0.420(0.35)$ & $\tau\left(\mathrm{N}-\mathrm{C}_{\alpha}\right)$ & 0.031 \\
$\phi\left(\mathrm{N}-\mathrm{C}_{\alpha}-\mathrm{H}_{\alpha}\right)$ & $0.350(0.80)$ & $\tau\left(\mathrm{C}_{\alpha}-\mathrm{C}\right)$ & 0.069 \\
$\phi\left(\mathrm{C}-\mathrm{C}_{\alpha}-\mathrm{H}_{\alpha}\right)$ & $0.278(0.48)$ & $\tau(\mathrm{C}==\mathrm{N})$ & 0.040 \\
$\phi\left(\mathrm{N}-\mathrm{C}_{\alpha}-\mathrm{C}\right)$ & $0.150(0.50)$ & $\tau\left(\mathrm{C}_{\beta}-\mathrm{C}_{\alpha}\right)$ & 0.047 \\
$\phi\left(\mathrm{N}-\mathrm{C}_{\alpha}-\mathrm{C}_{\beta}\right)$ & $0.110(0.50)$ & $\tau\left(\mathrm{C}_{\beta}-\mathrm{C}_{\gamma 1}\right)$ & 0.008 \\
$\phi\left(\mathrm{C}-\mathrm{C}_{\alpha}-\mathrm{C}_{\beta}\right)$ & $0.440(0.20)$ & $\tau\left(\mathrm{C}_{\beta}-\mathrm{C}_{\gamma 2}\right)$ & 0.008 \\
$\phi\left(\mathrm{C}_{\beta}-\mathrm{C}_{\alpha}-\mathrm{H}_{\alpha}\right)$ & $0.300(0.22)$ & & \\
& & &
\end{tabular}

${ }^{\mathrm{a}} v, \phi, \omega$, and $\tau$ denote stretch, angle bend, wag, and torsion, respectively. Non bonded force constants are given in parentheses.

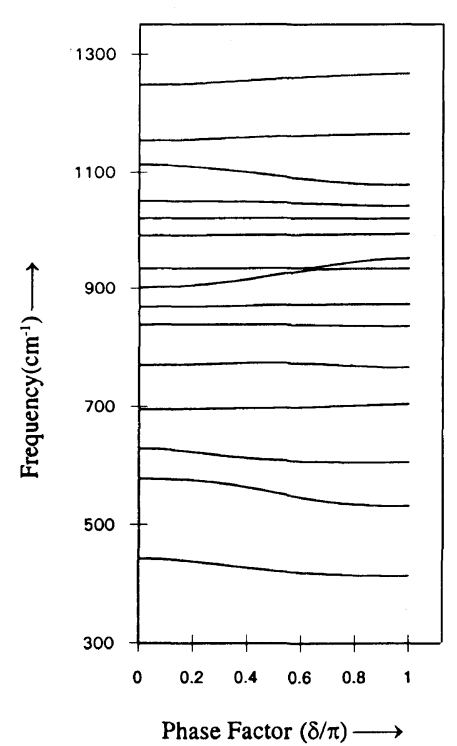

(a)

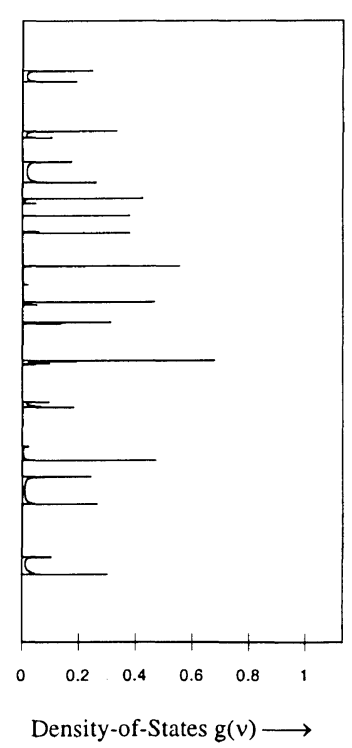

(b)
Figure 2. (a): Dispersion curves of $\alpha$ poly(L-valine) $\left(1300-300 \mathrm{~cm}^{-1}\right)$. (b): Density-of-states $g(v)\left(1300-300 \mathrm{~cm}^{-1}\right)$.

energy, entropy, specific heat, and enthalpy. The constant volume heat capacity $C_{\mathrm{v}}$ has been calculated using Debye's relation

$$
C_{\mathrm{v}}=\sum_{j} g\left(v_{j}\right) k N_{\mathrm{A}}\left(h v_{j} / k T\right)^{2} \frac{\exp \left(h v_{j} / k T\right)}{\left[\exp \left(h v_{j} / k T\right)-1\right]^{2}}
$$

with

$$
\int g\left(v_{j}\right) \mathrm{d} v_{j}=1
$$

The constant volume heat capacity $C_{\mathrm{v}}$, given by eq 2 is converted into constant pressure heat capacity $C_{\mathrm{p}}$ using the Nernst-Lindemann approximation ${ }^{12}$

$$
C_{\mathrm{p}}-C_{\mathrm{v}}=3 R A_{0}\left(C_{\mathrm{p}}^{2} T / C_{\mathrm{v}} T_{\mathrm{m}}^{0}\right)
$$

where $A_{0}$ is a constant of an universal value (3.9干

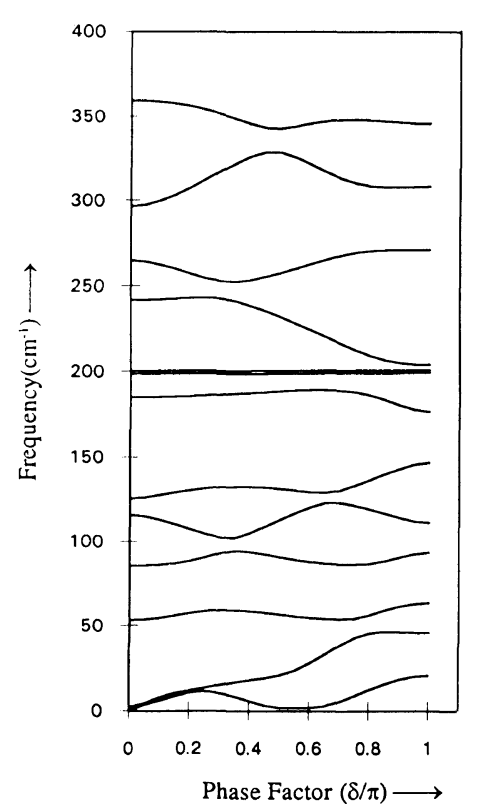

(a)

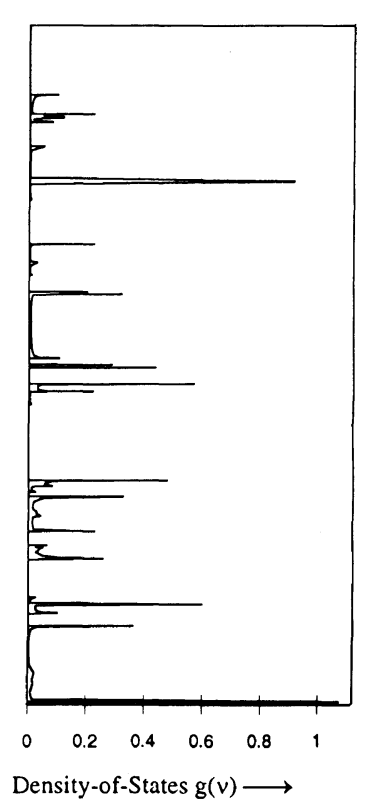

(b)
Figure 3. (a): Dispersion curves of $\alpha$ poly (L-valine) (below $400 \mathrm{~cm}^{-1}$ ). (b): Density-of-states $g(v)$ (below $400 \mathrm{~cm}^{-1}$ ).

$2.4) \times 10^{-3}(\mathrm{~K} \mathrm{~mol}) \mathrm{J}^{-1}$ and $T_{\mathrm{m}}^{0}$ is the estimated equilibrium melting temperature.

\section{RESULTS AND DISCUSSION}

The optically active modes of $18_{5}$ helix correspond to the phase values $\delta=0, \psi$, and $2 \psi$, where $\psi$ is the angle of rotation about the helix axis which separates the adjacent units. For $\alpha$ PLV $\psi=5 \pi / 9$. The modes corresponding to $\delta=0$ and $\psi$ are infrared as well as Raman active and $\delta=2 \psi$ gives only Raman active modes. In $\alpha$ PLV there are 16 atoms per residue unit which gives rise to 48 dispersion curves. The vibrational frequencies were calculated for the values of $\delta$ ranging from 0 to $\pi$ in steps of $0.05 \pi$. The calculated frequencies at $\delta=0$ and $5 \pi / 9$ are compared with the observed ones. Initially the force constants for backbone atoms were transferred from $\alpha$ poly(L-alanine $)^{13}$ and those for side chain atoms were transferred from our earlier studies on $\beta$ PLV. ${ }^{1}$ The force constants for the motion of side chain atoms are not very different. However those for the motion of the backbone atoms had to be fitted. The force constants which give best fit to the experimental data are given in Table I. The modes below $1300 \mathrm{~cm}^{-1}$ show appreciable dispersion and are shown in Figures 2(a) and 3(a). The lowest lying curves $(\delta=0$ and $\delta=5 \pi / 9, v=0)$ are the four acoustic modes [Figure 3(a)] which correspond to the rotation about the helix axis and three translations parallel and perpendicular to the helix axis. The dihedral angles $\phi, \psi$, and $\chi_{1}$ are taken from the conformational analysis of macromolecules by Scherage et al. ${ }^{5}$ Several other polypeptides are known to exist in $\alpha$ helical conformation viz. poly(L-alanine), poly(L-leucine), poly(Lglutamic acid), etc. ${ }^{13-15}$ Despite the identical $\alpha$ helical backbone, significantly different frequencies are calculated for $\alpha$-poly(L-valine), which clearly demonstrate the influence of side-chain structure on main chain vibrational modes. These are shown in Table V. For the sake 
of simplicity the normal vibrational frequencies are discussed under three separate heads viz. pure backbone modes, pure side chain modes and mixed modes.

\section{SIDE CHAIN MODES}

Side chain modes of $\alpha$ PLV involving the motion of dimethyl group are calculated at nearly same frequencies as in $\beta$ PLV. $\mathrm{CH}_{3}$ scissorring mode is observed at $1461 \mathrm{~cm}^{-1}$. Methyl rocking modes are calculated at 1020 and $934 \mathrm{~cm}^{-1}$ corresponding to observed frequencies at 1021 and $939 \mathrm{~cm}^{-1}$ respectively. The modes calculated at 1050,991 , and $867 \mathrm{~cm}^{-1}$ also have a dominant contribution of methyl rock in addition to $\mathrm{C}_{\beta}-\mathrm{C}_{\gamma}$ stretch (in the modes at 991 and $867 \mathrm{~cm}^{-1}$ ) or $\mathrm{C}_{\alpha}-\mathrm{C}_{\beta}$ stretch (in the mode at $1050 \mathrm{~cm}^{-1}$ ). With very little changes in the side chain force constants it was possible to fit the side chain vibrational modes of $\alpha$ PLV. These modes are given in Table II.

\section{BACKBONE MODES}

Backbone of PLV chain consists of amide groups

Table II. Pure side chain modes ${ }^{a}$

\begin{tabular}{|c|c|c|}
\hline Calcd & Obsd & Assignment $(\% \text { PED })^{\mathbf{b}}(\delta=0)$ \\
\hline 2968 & 2966 & $v\left(\mathrm{C}_{\alpha}-\mathrm{H}_{\alpha}\right)(98)$ \\
\hline 2948 & 2945 & $v\left(\mathrm{C}_{\beta}-\mathrm{H}_{\beta}\right)(14)+v\left(\mathrm{C}_{\gamma 1}-\mathrm{H}_{\gamma 1}\right)(42)+v\left(\mathrm{C}_{\gamma 2}-\mathbf{H}_{\gamma 2}\right)(43)$ \\
\hline 2946 & & $v\left(\mathrm{C}_{\gamma 1}-\mathrm{H}_{\gamma 1}\right)(50)+v\left(\mathrm{C}_{\gamma 2}-\mathrm{H}_{\gamma 2}\right)(49)$ \\
\hline 2935 & 2935 & $v\left(\mathrm{C}_{\beta}-\mathbf{H}_{\beta}\right)(85)+v\left(\mathrm{C}_{\gamma 1}-\mathbf{H}_{\gamma 1}\right)(6)+v\left(\mathrm{C}_{\gamma 2}-\mathrm{H}_{\gamma 2}\right)(6)$ \\
\hline 2906 & 2900 & $v\left(\mathrm{C}_{\gamma 1}-\mathrm{H}_{\gamma 1}\right)(49)+v\left(\mathrm{C}_{\gamma 2}-\mathrm{H}_{\gamma 2}\right)(49)$ \\
\hline 2905 & & $v\left(\mathrm{C}_{\gamma 1}-\mathrm{H}_{\gamma 1}\right)(50)+v\left(\mathrm{C}_{\gamma^{2}}-\mathrm{H}_{\gamma 2}\right)(49)$ \\
\hline 2905 & & $v\left(\mathrm{C}_{\gamma 1}-\mathrm{H}_{\gamma 1}\right)(48)+v\left(\mathrm{C}_{\gamma 2}-\mathrm{H}_{\gamma 2}\right)(50)$ \\
\hline 2905 & & $v\left(\mathrm{C}_{\gamma 1}-\mathrm{H}_{\gamma 1}\right)(50)+v\left(\mathrm{C}_{\gamma 2}-\mathrm{H}_{\gamma 2}\right)(48)$ \\
\hline 1472 & 1461 & $\phi\left(\dot{H}_{\gamma 1}-\mathrm{C}_{\gamma 1}-\mathrm{H}_{\gamma 1}\right)(44)+\phi\left(\dot{H}_{\gamma 2}-\mathrm{C}_{\gamma 2}-\mathrm{H}_{\gamma 2}\right)(49)$ \\
\hline 1470 & & $\phi\left(\mathrm{H}_{\gamma 1}-\mathrm{C}_{\gamma 1}-\mathrm{H}_{\gamma 1}\right)(53)+\phi\left(\mathrm{H}_{\gamma 2}-\mathrm{C}_{\gamma 2}-\mathrm{H}_{\gamma 2}\right)(40)$ \\
\hline 1470 & & $\phi\left(\mathrm{H}_{\gamma 1}-\mathrm{C}_{\gamma 1}-\mathrm{H}_{\gamma 1}\right)(41)+\phi\left(\mathrm{H}_{\gamma 2}-\mathrm{C}_{\gamma 2}-\mathrm{H}_{\gamma 2}\right)(52)$ \\
\hline 1469$\lrcorner$ & & $\phi\left(\mathrm{H}_{\gamma 1}-\mathrm{C}_{\gamma 1}-\mathrm{H}_{\gamma 1}\right)(49)+\phi\left(\mathrm{H}_{\gamma 2}-\mathrm{C}_{\gamma 2}-\mathrm{H}_{\gamma 2}\right)(45)$ \\
\hline 1396 & 1396 & $\begin{array}{l}\phi\left(\mathrm{C}_{\beta}-\mathrm{C}_{\gamma 1}-\mathrm{H}_{\gamma 1}\right)(25)+\phi\left(\mathrm{H}_{\gamma 1}-\mathrm{C}_{\gamma 1}-\mathrm{H}_{\gamma 1}\right)(23)+ \\
\phi\left(\mathrm{H}_{\gamma 2} 1-\mathrm{C}_{\gamma 2}-\mathrm{H}_{\gamma 2}\right)(22)+\phi\left(\mathrm{C}_{\beta}-\mathrm{C}_{\gamma 2}-\mathrm{H}_{\gamma 2}\right)(23)\end{array}$ \\
\hline 1303 & 1297 & $v\left(\mathrm{C}_{\alpha}-\mathrm{C}_{\beta}\right)(8)+\phi\left(\mathrm{H}_{\beta}-\mathrm{C}_{\beta}-\mathrm{C}_{\alpha}\right)(39)+\phi\left(\mathrm{C}_{\gamma 2}-\mathrm{C}_{\beta}-\mathrm{H}_{\beta}\right)(36)$ \\
\hline 1050 & 1054 & $\begin{array}{l}v\left(\mathrm{C}_{\alpha}-\mathrm{C}_{\beta}\right)(21)+\phi\left(\mathrm{C}_{\beta}-\mathrm{C}_{\alpha}-\mathrm{H}_{\alpha}\right)(6)+\phi\left(\mathrm{H}_{\beta}-\mathrm{C}_{\beta}-\mathrm{C}_{\alpha}\right)(10)+ \\
\phi\left(\mathrm{C}_{\beta}-\mathrm{C}_{\gamma 1}-\mathrm{H}_{\gamma 1}\right)(18)+\phi\left(\mathrm{C}_{\beta}-\mathrm{C}_{\gamma 2}-\mathrm{H}_{\gamma 2}\right)(22)\end{array}$ \\
\hline 1020 & 1021 & $\phi\left(\mathrm{C}_{\beta}-\mathrm{C}_{\gamma 1}-\mathrm{H}_{\gamma 1}\right)(39)+\phi\left(\mathrm{C}_{\beta}-\mathrm{C}_{\gamma 2}-\mathrm{H}_{\gamma 2}\right)(38)$ \\
\hline 991 & 992 & $v\left(\mathrm{C}_{\beta}-\mathrm{C}_{\gamma 1}\right)(13)+\phi\left(\mathrm{C}_{\beta}-\mathrm{C}_{\gamma 1}-\mathrm{H}_{\gamma 1}\right)(33)+v\left(\mathrm{C}_{\beta}-\mathrm{C}_{\gamma 2}\right)(15)$ \\
\hline 934 & 939 & $\phi\left(\mathrm{C}_{\beta}-\mathrm{C}_{\gamma 1}-\mathrm{H}_{\gamma 1}\right)(45)+\phi\left(\mathrm{C}_{\beta}-\mathrm{C}_{\gamma 2}-\mathrm{H}_{\gamma 2}\right)(47)$ \\
\hline 867 & 869 & $\begin{array}{l}v\left(\mathrm{C}_{\beta}-\mathrm{C}_{\gamma 1}\right)(25)+\phi\left(\mathrm{C}_{\beta}-\mathrm{C}_{\gamma 1}-\mathrm{H}_{\gamma 1}\right)(22)+v\left(\mathrm{C}_{\beta}-\mathrm{C}_{\gamma 2}\right)(31)+ \\
\phi\left(\mathrm{C}_{\beta}-\mathrm{C}_{\gamma 2}-\mathrm{H}_{\gamma 2}\right)(12)\end{array}$ \\
\hline 200 & - & $\tau\left(\mathbf{C}_{\beta}-\mathrm{C}_{\gamma 1}\right)(39)+\tau\left(\mathrm{C}_{\beta}-\mathrm{C}_{\gamma 2}\right)(58)$ \\
\hline 198 & - & $\tau\left(\mathrm{C}_{\beta}-\mathrm{C}_{\gamma_{1}}\right)(46)+\tau\left(\mathrm{C}_{\beta}-\mathrm{C}_{\gamma 2}\right)(28)$ \\
\hline
\end{tabular}

${ }^{a}$ All frequencies are in $\mathrm{cm}^{-1}$. ${ }^{\mathrm{b}}$ PED, potential energy distribution. joined to $\mathrm{C}_{\alpha}$ atoms. The modes involving the motions of these atoms along with their assignments are given in Table III. The $\mathrm{N}-\mathrm{H} . . . \mathrm{O}==\mathrm{C}$ hydrogen bond along with the amide modes play an important role in structural diagnosis of polypeptides and proteins. ${ }^{16}$ The inter and intra chain hydrogen bonds in $\beta$ and $\alpha$ forms of PLV are $2.73 \AA$ and $2.80 \AA$ respectively implying thereby that the hydrogen bond is weaker in $\alpha$ conformation. This difference is also reflected in the relative magnitudes of force constants (For $\alpha$ PLV $v(\mathrm{~N}-\mathrm{H})=$ 5.390, $v(\mathrm{C}==\mathrm{O})=8.58 \mathrm{md} \AA^{-1}$, and for $\beta$ PLV $v(\mathrm{~N}-\mathrm{H})$ $\left.=5.360, v(\mathrm{C}==\mathrm{O})=8.225 \mathrm{md}^{-1}\right)$, and frequencies for the $\mathrm{N}-\mathrm{H}$ and $\mathrm{C}==\mathrm{O}$ stretches.

A comparison of amide modes of $\alpha$ PLV with those of the $\beta$ PLV and other $\alpha$ helical polypeptides have been made and it is observed that amide I and amide II are well in the range of other $\alpha$ helical polypeptides. The amide $\mathrm{A}$ and amide I modes are sensitive to the strength of $\mathrm{N}-\mathrm{H} . . \mathrm{O}==\mathrm{C}$ hydrogen bonding. The amide $\mathrm{A}$ in $\alpha$ PLV is observed at $3293 \mathrm{~cm}^{-1}$ and at $3290 \mathrm{~cm}^{-1}$ in $\beta$ PLV. Since in this case the frequency difference of $3 \mathrm{~cm}^{-1}$ is well within the experimental error, it is difficult to conclude that the frequency difference arises because of different strengths of hydrogen bonding. The amide I mode at $1655 \mathrm{~cm}^{-1}$ in $\alpha$ PLV is higher than amide I at $1638 \mathrm{~cm}^{-1}$ in $\beta \mathrm{PLV}$. The amide III bands for $\alpha \mathrm{PLV}$ are reported at 1253,1246 , and $1237 \mathrm{~cm}^{-1}$ by Yamashita and Yamashita. ${ }^{7}$ The calculated frequencies at $\delta=0$ and $\delta=5 \pi / 9$ are at 1248 and $1253 \mathrm{~cm}^{-1}$ respectively. The peak observed at $1237 \mathrm{~cm}^{-1}$ by Yamashita et al. may be due to imperfections in the helical structure for example, fraying at the ends or breaks in the helical continuity.

\section{MIXED MODES}

In $\alpha$ PLV there is large coupling of main chain vibrations with side chain vibrations below $1400 \mathrm{~cm}^{-1}$ and most of these modes can be regarded as mixed modes. Table IV shows assignments and potential energy distribution of such modes.

The observed peak at $1114 \mathrm{~cm}^{-1}$ has been assigned to skeletal stretch. At $\delta=0$ this mode is a pure backbone mode $\left[v\left(\mathrm{~N}-\mathrm{C}_{\alpha}\right)(56 \%)+v\left(\mathrm{C}_{\alpha}-\mathrm{C}\right)(27 \%)\right]$ as $\delta$ increases $\left(\mathrm{C}_{\alpha}-\mathrm{C}_{\beta}\right)$ stretch starts mixing in this mode. In $\alpha$ poly(L-glutamic acid) ${ }^{15}$ also, this mode is observed at $1117 \mathrm{~cm}^{-1}$. This skeletal stretching mode reflecting the conformational differences is observed at $1090 \mathrm{~cm}^{-1}$ in $\beta$ PLV. The amides $\mathrm{V}$ and VI consist of asymmetric out-of-plane $\mathrm{N}-\mathrm{H}$ and $\mathrm{C}==\mathrm{O}$ vibrations, respectively.

Table III. Pure back-bone modes ${ }^{\mathrm{a}}$

\begin{tabular}{|c|c|c|c|c|c|}
\hline Calcd & Obsd & Assignment $(\%$ PED) $(\delta=0)$ & Calcd & Obsd & Assignment ( $\%$ PED) $(\delta=5 \pi / 9)$ \\
\hline 3293 & 3293 & $v(\mathrm{~N}-\mathrm{H})(99)$ & 3293 & 3293 & $v(\mathrm{~N}-\mathrm{H})(99)$ \\
\hline 1645 & 1655 & $v(\mathrm{C}==\mathrm{N})(20)+v(\mathrm{C}==\mathrm{O})(65) \quad\{$ Amide $\mathrm{I}\}$ & 1643 & 1650 & $v(\mathrm{C}==\mathrm{N})(21)+v(\mathrm{C}==\mathrm{O})(66)$ \\
\hline 1533 & 1535 & $\begin{array}{l}v(\mathrm{C}==\mathrm{N})(18)+v\left(\mathrm{~N}-\mathrm{C}_{\alpha}\right)(5)+\phi\left(\mathrm{C}=\stackrel{\mathrm{N}-\mathrm{H})(35)+}{\phi\left(\mathrm{C}_{\alpha}-\mathrm{N}-\mathrm{H}\right)(36)} \quad\{\text { Amide II }\}\right.\end{array}$ & 1532 & 1520 & $\begin{array}{l}v(\mathrm{C}==\mathrm{N})(16)+v\left(\mathrm{~N}-\mathrm{C}_{\alpha}\right)(5)+\phi(\mathrm{C}==\mathrm{N}-\mathrm{H})(37)+ \\
\phi\left(\mathrm{C}_{\alpha}-\mathrm{N}-\mathrm{H}\right)(37)\end{array}$ \\
\hline 1248 & 1246 & $\begin{array}{l}v(\mathrm{C}==\mathrm{N})(34)+v\left(\mathrm{~N}-\mathrm{C}_{\alpha}\right)(9)+v\left(\mathrm{C}_{\alpha}-\mathrm{C}\right)(8)+ \\
v(\mathrm{C}==\mathrm{O})(16)+\phi\left(\mathrm{C}_{\alpha}-\mathrm{N}-\mathrm{H}\right)(7) \quad\{\text { Amide III }\}\end{array}$ & 1259 & 1253 & $\begin{array}{l}v(\mathrm{C}==\mathrm{N})(31)+v\left(\mathrm{~N}-\mathrm{C}_{\alpha}\right)(15)+v\left(\mathrm{C}_{\alpha}-\mathrm{C}\right)(17)+ \\
v(\mathrm{C}==\mathrm{O})(12)+\phi\left(\mathrm{C}_{\alpha}-\mathrm{N}-\mathrm{H}\right)(6) \quad\{\text { Amide III }\}\end{array}$ \\
\hline
\end{tabular}

${ }^{a}$ All frequencies are in $\mathrm{cm}^{-1}$. 
Vibrational Stady of $\alpha$-Poly(L-valine)

Table IV. Mixed-modes ${ }^{\mathrm{a}}$

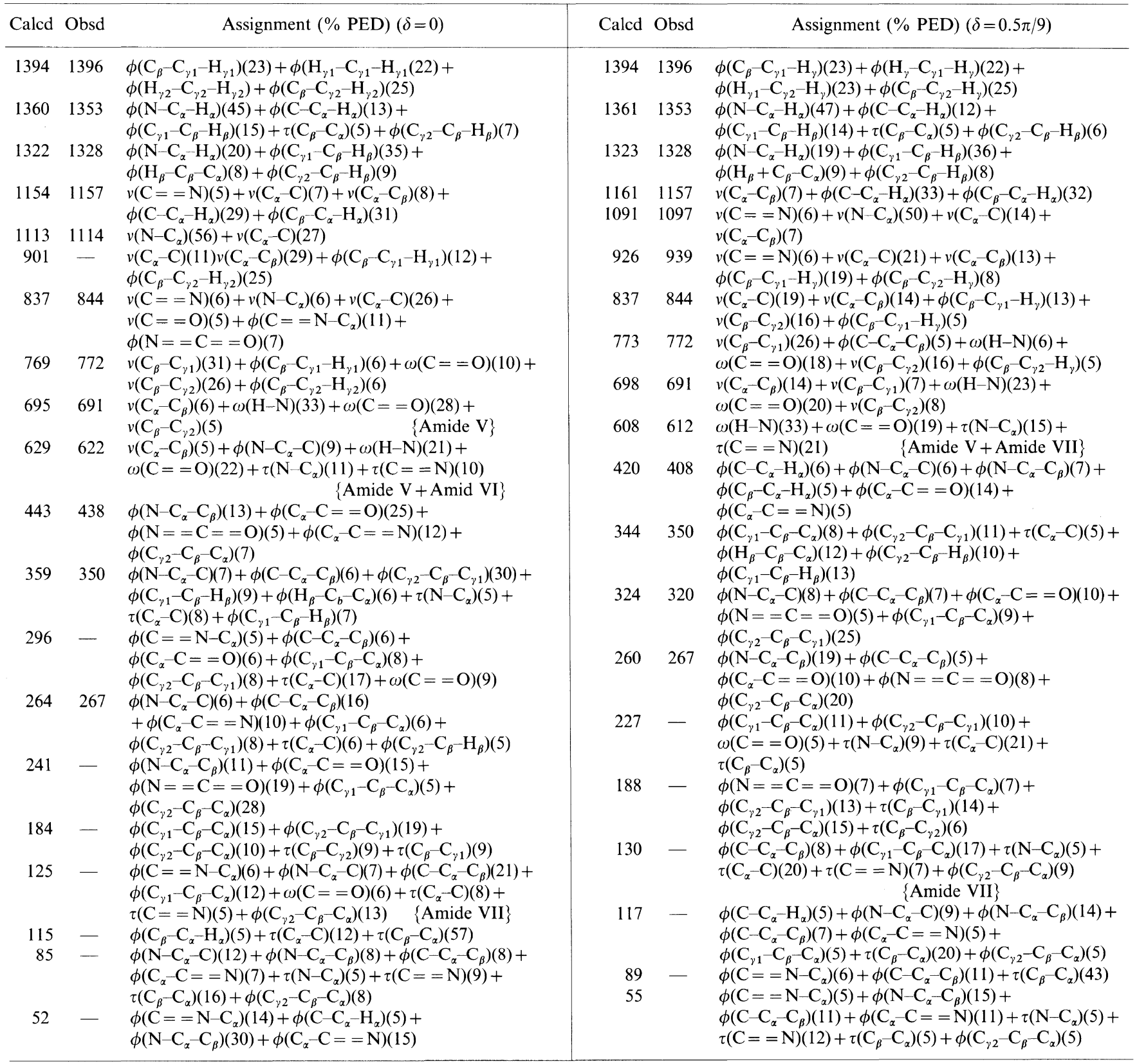

${ }^{\text {a }}$ All frequencies are in $\mathrm{cm}^{-1}$.

Table V. Comparison of amide modes of $\alpha$ PLV with those of $\beta$ PLV and other $\alpha$ helical polypeptides

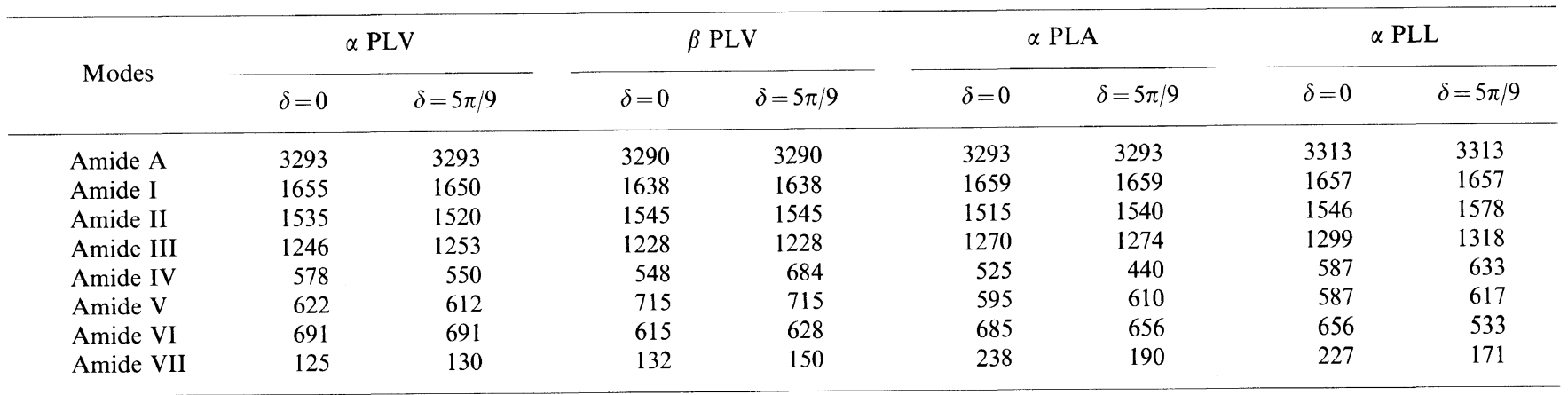

Two mixed modes mainly having amide $\mathrm{V}$ and amide VI are calculated at $629 \mathrm{~cm}^{-1}(\delta=0)$ and $608 \mathrm{~cm}^{-1}(\delta=$ $5 \pi / 9)$, while in the $\beta$ form these modes were calculated at $708 \mathrm{~cm}^{-1}(\delta=0)$ and $724 \mathrm{~cm}^{-1}(\delta=\pi)$. In case of $\alpha$
PLV there is a greater mixing of $\mathrm{N}-\mathrm{H}$ and $\mathrm{C}==\mathrm{O}$ wagging modes than in the case of $\beta$ form. This may possibly be due to stronger $\mathrm{N}-\mathrm{H} . . \mathrm{C}==\mathrm{O}$ intrachain interactions in $\alpha$ helical form. There is no such cor- 
responding interactions in the $\beta$ form.

The amide VII in $\alpha$ PLV is calculated at $125 \mathrm{~cm}^{-1}$ $(\delta=0)$. The corresponding frequency belonging to $5 \pi / 9$ is calculated at $130 \mathrm{~cm}^{-1}$. Unlike poly(L-alanine $)^{13}$ and poly(L-leucine),${ }^{14}$ the amide VII band in $\alpha$ PLV disperses towards higher frequency as it is repelled up at $\delta=0.70 \pi$ by the mode at $115 \mathrm{~cm}^{-1}$.

\section{DISPERSION CURVES}

Modes below $1300 \mathrm{~cm}^{-1}$ show appreciable dispersion and are plottd in Figures 2(a) and 3(a). One of the prominant features seen in the dispersion curves of $\alpha$ poly(L-valine) is the repulsion of various modes. Pair of modes showing repulsion are $\left(934 \mathrm{~cm}^{-1}\right.$ and $\left.901 \mathrm{~cm}^{-1}\right)$, $\left(359 \mathrm{~cm}^{-1}\right.$ and $\left.296 \mathrm{~cm}^{-1}\right),\left(125 \mathrm{~cm}^{-1}\right.$ and $\left.115 \mathrm{~cm}^{-1}\right)$, and $\left(115 \mathrm{~cm}^{-1}\right.$ and $\left.85 \mathrm{~cm}^{-1}\right)$. An examination of potential energy distribution (PED) of the modes $\left(359 \mathrm{~cm}^{-1}\right.$ and $296 \mathrm{~cm}^{-1}$ ) indicates that these modes approach each other, PED of the two modes start mixing and at a particular value of $\delta$ they are repelled but there is no exchange of character between them. All other pairs of modes (listed in Table VI) approach each other, exchange character and then get repelled. On comparison of dispersion curves of $\alpha$ and $\beta$ form of poly(L-valine) it is observed that in $\alpha$ PLV repulsion between pair of modes occurs below $300 \mathrm{~cm}^{-1}$ (except between $934 \mathrm{~cm}^{-1}$ and $901 \mathrm{~cm}^{-1}$ ) while in $\beta$ PLV it is seen in the frequency range $550 \mathrm{~cm}^{-1}$ and $900 \mathrm{~cm}^{-1}$. No crossing-over of modes is seen in $\alpha$ PLV as in the case of $\beta$ PLV. This characteristic feature arises due to symmetry and coupling of corresponding modes. The dispersion curves belonging to same symmetry species do not cross. ${ }^{17}$

Another interesting feature of the dispersion curves of $\alpha$ PLV is the tendency of pair of modes involving the motion of $\mathrm{C}_{\alpha}$ atoms $\left(359 \mathrm{~cm}^{-1}\right.$ and $296 \mathrm{~cm}^{-1} ; 125 \mathrm{~cm}^{-1}$ and $115 \mathrm{~cm}^{-1} ; 52 \mathrm{~cm}^{-1}$ and rotational acoustic mode) to come closer near the helix angle. Similar phenomenon is observed in the case of poly(L-alanine) ( $\alpha$ helix) and poly(tetrafluoroethylene) (15/7 helix) ${ }^{13,18}$ In these poly- meric systems the effect can be attributed to the presence of strong intramolecular interactions which stabilize the helical structure. This is supported by a comparison of the profile and meandering of the dispersion curves in intramolecularly stabilized ( $\alpha$ helix) and intermolecularly stabilized ( $\beta$ form) systems. The strong intramolecular interactions give rise to the strong coupling of the modes and this coupling is stronger when the tendency of the dispersion curves to come closer together occurs near the phase angle $\delta$ being equal to helix angle $\psi$ (in the neighborhood of mechanical resonance). In case of $\alpha$ poly(L-alanine) (PLA) and $\alpha$ poly(L-valine) it is the intrachain hydrogen bonding and non bonded interactions while in case of poly(tertrafluoroethylene) (PTFE) it is the strong interaction between the Fluorine atoms. The helical conformations have relatively stronger non bonded intrachain interactions between different residues in the same chain as compared with the extended structure.

\section{FREQUENCY DISTRIBUTION FUNCTION AND HEAT CAPACITY OF $\alpha$ PLV}

Frequency distribution function which expresses the way energy is distributed among the various branches of normal modes in the chain is plotted in Figures 2(b) and 3(b). The peaks in the frequency distribution curves indicate the regions of high density-of-states. From the knowledge of density-of-states, heat capacity is calculated for $\alpha$ PLV in the temperature region $230-390 \mathrm{~K}$. $C_{\mathrm{p}}$ is calculated using Lindermann's approximation with $A_{0}=3.9 \times 10^{-3}(\mathrm{~K} \mathrm{~mol}) \mathrm{J}^{-1}$ and $T_{\mathrm{m}}^{0}$ the equilibrium melting temperature $=573 \mathrm{~K}$. The value of $A_{0}$ is the same as used for the $\beta$ conformation. A comparison of specific heat contribution by the skeletal, side chain and mixed modes in the $\alpha$ and $\beta$ forms are shown in Figures 4(a), (b), and (c). The total heat capacity is shown in Figure 5. The triangles give $C_{\mathrm{p}}$ for the $\beta$ form (experimental). The specific heat contribution of the backbone and side chain modes is higher for the $\alpha$ form but it is reversed

Table VI. Pair of modes that repel and exchange character

\begin{tabular}{|c|c|c|c|c|c|c|c|}
\hline \multirow{2}{*}{$\begin{array}{l}\text { Freq. } \\
(\delta=0)\end{array}$} & \multirow{2}{*}{$\delta^{\sharp} / \pi^{\mathrm{a}}$} & \multicolumn{3}{|r|}{ Before exchange } & \multicolumn{3}{|r|}{ After exchange } \\
\hline & & $\delta^{*} / \pi^{\mathrm{b}}$ & Freq. & PED & $\delta^{*} / \pi^{\mathrm{b}}$ & Freq. & PED \\
\hline 934 & 0.65 & 0.60 & 935 & $\phi\left(\mathrm{C}_{\beta}-\mathrm{C}_{\gamma 1}-\mathrm{H}_{\gamma}\right)(32)+\phi\left(\mathrm{C}_{\beta}-\mathrm{C}_{\gamma 2}-\mathrm{H}_{\gamma}\right)(50)$ & 0.70 & 939 & $\begin{array}{l}v(\mathrm{C}==\mathrm{N})(6)+v\left(\mathrm{C}_{\alpha}-\mathrm{C}\right)(23)+v\left(\mathrm{C}_{\alpha}-\mathrm{C}_{\beta}\right)(8)+ \\
\phi\left(\mathrm{C}_{\beta}-\mathrm{C}_{\gamma 1}-\mathrm{H}_{\gamma}\right)(18)+\phi\left(\mathrm{C}_{\beta}-\mathrm{C}_{\gamma 2}-\mathrm{H}_{\gamma}\right)(23)\end{array}$ \\
\hline 901 & & 0.60 & 930 & $\begin{array}{l}v(\mathrm{C}==\mathrm{N})(6)+v\left(\mathrm{C}_{\alpha}-\mathrm{C}\right)(20)+v\left(\mathrm{C}_{\alpha}-\mathrm{C}_{\beta}\right)(11)+ \\
v\left(\mathrm{C}_{\alpha}-\mathrm{C}_{\beta}\right)(8)+\phi\left(\mathrm{C}_{\beta}-\mathrm{C}_{\gamma 1}-\mathrm{H}_{\gamma}\right)(28)+ \\
\phi\left(\mathrm{C}_{\beta}-\mathrm{C}_{\gamma 2}-\mathrm{H}_{\gamma}\right)(23)\end{array}$ & 0.70 & 933 & $\phi\left(\mathrm{C}_{\beta}-\mathrm{C}_{\gamma 1}-\mathrm{H}_{\gamma}\right)(49)+\phi\left(\mathrm{C}_{\beta}-\mathrm{C}_{\gamma 2}-\mathrm{H}_{\gamma}\right)(32)$ \\
\hline 125 & 0.70 & 0.65 & 129 & $\begin{array}{l}\phi\left(N-C_{\alpha}-C_{\beta}\right)(7)+\phi\left(C-C_{\alpha}-C_{\beta}\right)(11)+ \\
\phi\left(C_{\gamma 1}-C_{\beta}-C_{\alpha}\right)(19)+\tau\left(N-C_{\alpha}\right)(5)+\tau\left(C_{\alpha}-C\right)(15)+ \\
\tau(C==N)(6)+\phi\left(C_{\gamma 2}-C_{\beta}-C_{\alpha}\right)(11)\end{array}$ & 0.75 & 133 & $\begin{array}{l}\phi\left(\mathrm{C}==\mathrm{N}-\mathrm{C}_{\alpha}\right)(5)+\phi\left(\mathrm{N}-\mathrm{C}_{\alpha}-\mathrm{C}_{\beta}\right)(10)+ \\
\phi\left(\mathrm{C}-\mathrm{C}_{\alpha}-\mathrm{C}_{\beta}\right)(9)+\phi\left(\mathrm{C}_{\alpha}-\mathrm{C}==\mathrm{N}\right)(5)+ \\
\phi\left(\mathrm{C}_{\gamma 1}-\mathrm{C}_{\beta}-\mathrm{C}_{\alpha}\right)(11)+\tau\left(\mathrm{C}_{\alpha}-\mathrm{C}\right)(7)+\phi\left(\mathrm{C}_{\gamma 2}-\mathrm{C}_{\beta}-\mathrm{C}_{\alpha}\right)(7)+ \\
\tau\left(\mathrm{C}_{\beta}-\mathrm{C}_{\alpha}\right)(11)\end{array}$ \\
\hline 115 & & 0.65 & 102 & $\begin{array}{l}\phi\left(\mathrm{C}-\mathrm{C}_{\alpha}-\mathrm{H}_{\alpha}\right)(16)+\phi\left(\mathrm{N}-\mathrm{C}_{\alpha}-\mathrm{C}\right)(11)+ \\
\phi\left(\mathrm{N}-\mathrm{C}_{\alpha}-\mathrm{C}_{\beta}\right)(12)+\phi\left(\mathrm{C}-\mathrm{C}_{\alpha}-\mathrm{C}_{\beta}\right)(5)+\tau\left(\mathrm{C}_{\alpha}-\mathrm{C}\right)(6)+ \\
\tau\left(\mathrm{C}_{\beta}-\mathrm{C}_{\alpha}\right)(20)\end{array}$ & 0.75 & 122 & $\begin{array}{l}\phi\left(N-C_{\alpha}-\mathrm{C}\right)(9)+\phi\left(N-\mathrm{C}_{\alpha}-\mathrm{C}_{\beta}\right)(10)+\phi\left(\mathrm{C}-\mathrm{C}_{\alpha}-\mathrm{C}_{\beta}\right)(7)+ \\
\phi\left(\mathrm{C}_{\gamma 1}-\mathrm{C}_{\beta}-\mathrm{C}_{\alpha}\right)(11)+\tau\left(\mathrm{C}_{\alpha}-\mathrm{C}\right)(16)+\tau(\mathrm{C}==\mathrm{N})(5)+ \\
\tau\left(\mathrm{C}_{\beta}-\mathrm{C}_{\alpha}\right)(13)+\phi\left(\mathrm{C}_{\gamma 2}-\mathrm{C}_{\beta}-\mathrm{C}_{\alpha}\right)(5)\end{array}$ \\
\hline 115 & 0.40 & 0.35 & 102 & $\begin{array}{l}\phi\left(\mathrm{N}-\mathrm{C}_{\alpha}-\mathrm{C}_{\beta}\right)(11)+\phi\left(\mathrm{C}-\mathrm{C}_{\alpha}-\mathrm{C}_{\beta}\right)(7)+\tau\left(\mathrm{C}_{\beta}-\mathrm{C}_{\alpha}\right)(50)+ \\
\phi\left(\mathrm{C}_{\gamma 2}-\mathrm{C}_{\beta}-\mathrm{C}_{\alpha}\right)(9)\end{array}$ & 0.45 & 109 & $\begin{array}{l}\phi\left(\mathrm{C}-\mathrm{C}_{\alpha}-\mathrm{H}_{\alpha}\right)(5)+\phi\left(\mathrm{N}-\mathrm{C}_{\alpha}-\mathrm{C}\right)(9)+ \\
\phi\left(\mathrm{N}-\mathrm{C}_{\alpha}-\mathrm{C}_{\beta}\right)(15)+\phi\left(\mathrm{C}-\mathrm{C}_{\alpha}-\mathrm{C}_{\beta}\right)(8)+ \\
\phi\left(\mathrm{C}_{\alpha}-\mathrm{C}==\mathrm{N}\right)(5)+\phi\left(\mathrm{C}_{\gamma 1}-\mathrm{C}_{\beta}-\mathrm{C}_{\alpha}\right)(5)+ \\
\tau\left(\mathrm{C}_{\beta}-\mathrm{C}_{\alpha}\right)(24)+\phi\left(\mathrm{C}_{\gamma 2}-\mathrm{C}_{\beta}-\mathrm{C}_{\alpha}\right)(7)\end{array}$ \\
\hline 85 & & 0.35 & 94 & $\begin{array}{l}\phi\left(\mathrm{C}==\mathrm{N}-\mathrm{C}_{\alpha}\right)(8)+\phi\left(\mathrm{N}-\mathrm{C}_{\alpha}-\mathrm{C}\right)(21)+ \\
\phi\left(\mathrm{C}-\mathrm{C}_{\alpha}-\mathrm{C}_{\beta}\right)(16)+\phi\left(\mathrm{C}_{\beta}-\mathrm{C}_{\alpha}-\mathrm{H}_{\alpha}\right)(6)+\tau\left(\mathrm{C}_{\alpha}-\mathrm{C}\right)(7)+ \\
\tau\left(\mathrm{C}_{\beta}-\mathrm{C}_{\alpha}\right)(13)\end{array}$ & 0.45 & 92 & $\begin{array}{l}\phi\left(\mathrm{C}==\mathrm{N}-\mathrm{C}_{\alpha}\right)(6)+\phi\left(\mathrm{N}-\mathrm{C}_{\alpha}-\mathrm{C}\right)(6)+ \\
\phi\left(\mathrm{C}-\mathrm{C}_{\alpha}-\mathrm{C}_{\beta}\right)(14)+\tau\left(\mathrm{C}_{\alpha}-\mathrm{C}\right)(5)+\tau\left(\mathrm{C}_{\beta}-\mathrm{C}_{\alpha}\right)(39)\end{array}$ \\
\hline
\end{tabular}

${ }^{\mathrm{a}}$ \# marked $\delta$ corresponds to repulsion points. ${ }^{\mathrm{b}} *$ marked $\delta$ corresponds to the points before after repulsion. 


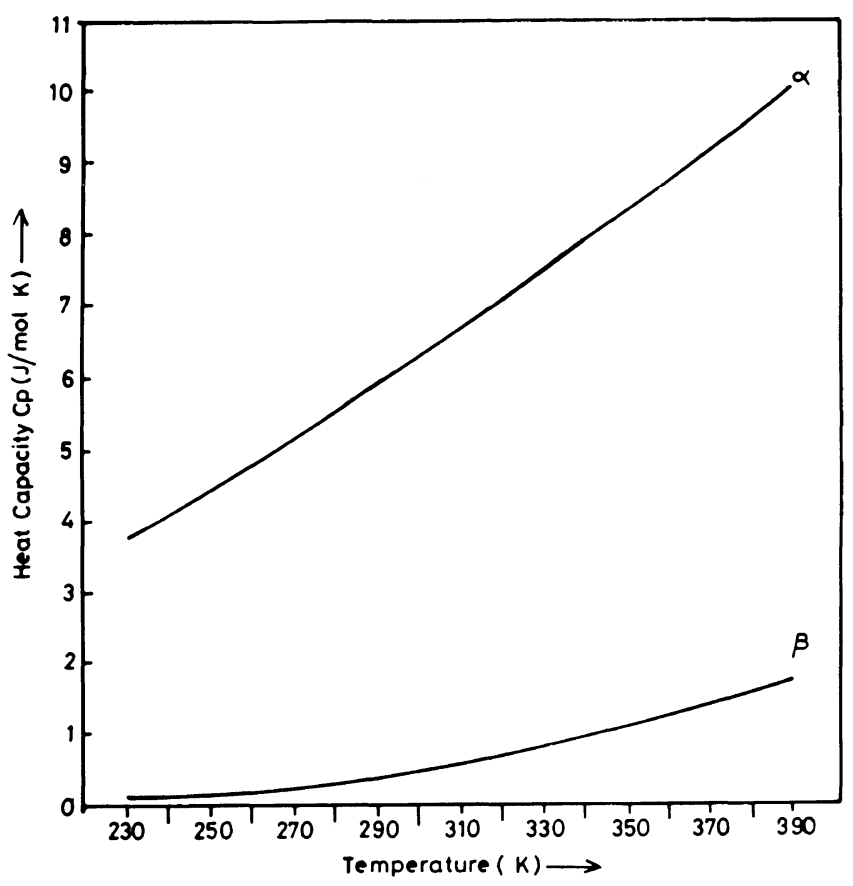

(a)

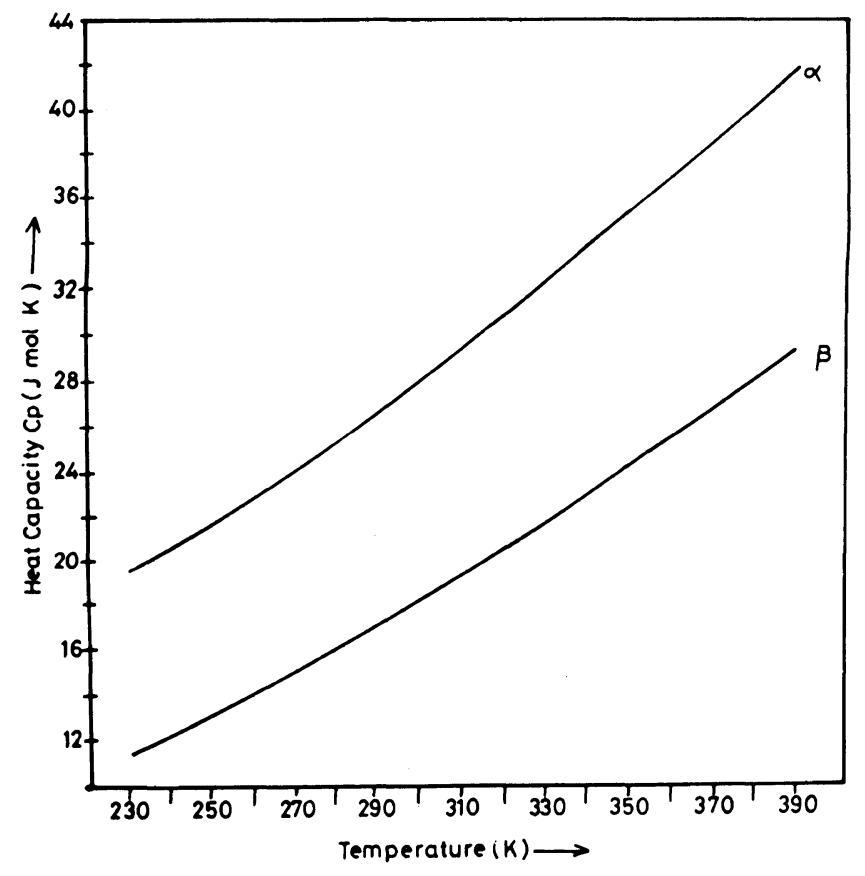

(b)

for the mixed modes. For the mixed modes the contribution in the $\beta$ form is greater than the $\alpha$ form. However overall value of heat capacity for the $\beta$ form remaining lower than $\alpha$ form. Since heat capacity is sensitive to low frequency modes, the overall variation depends on the relative weight of such modes for the backbone, side-chain and mixed modes. Such measurements and evaluation of heat capacity, if resolved in different states, can give information about the proportion of a polypeptide which is in $\alpha$ helical or $\beta$ sheet structure. Similarly conformation-states distribution is necessary in evaluating the basic thermodynamics of enzyme reaction ${ }^{19}$ which takes place always in a definite state.

A comparison of dispersion curves of $\alpha$ and $\beta$ PLV

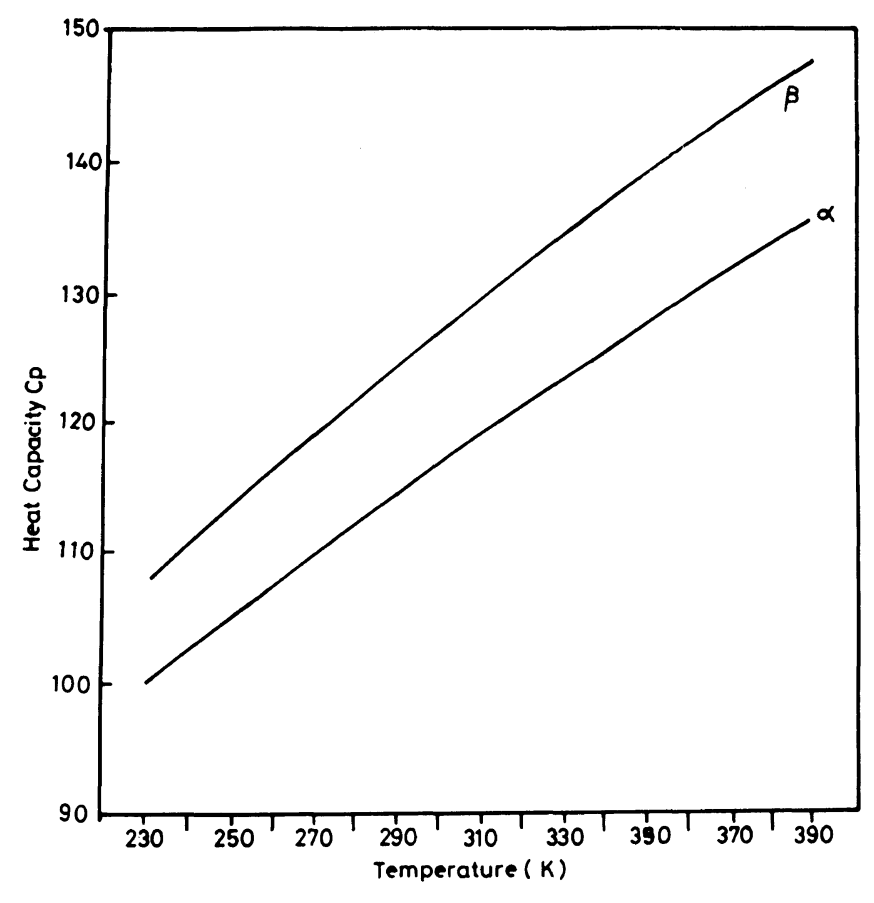

(c)

Figure 4. (a): Contribution of backbone modes to the heat capacity in $\alpha$ and $\beta$ forms. (b): Contribution of side-chain modes to the heat capacity in $\alpha$ and $\beta$ forms. (c): Contribution of mixed modes to the heat capacity in $\alpha$ and $\beta$ forms.

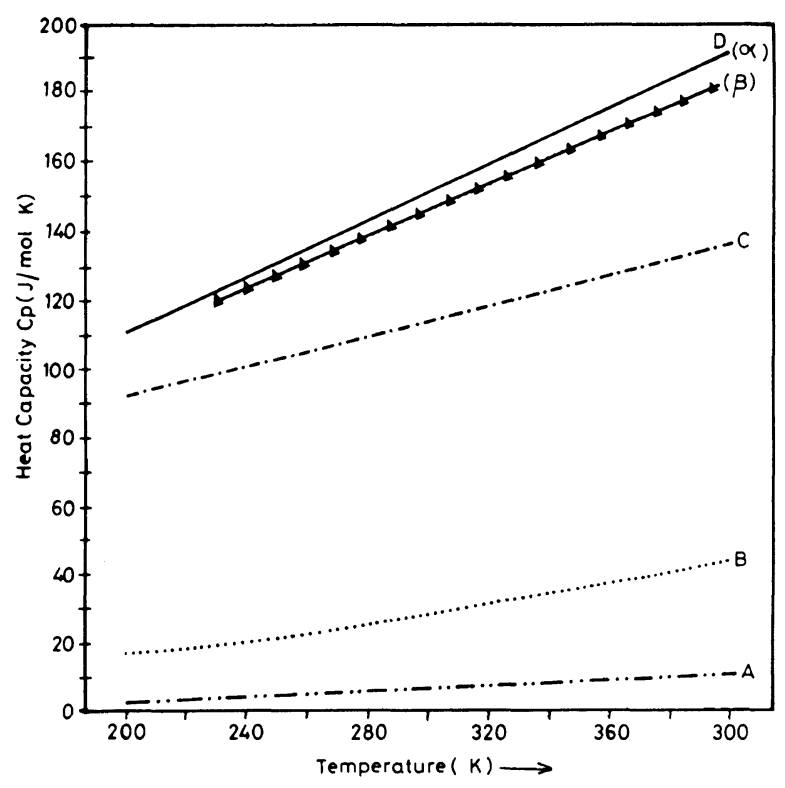

Figure 5. Variation of heat capacity with temperature. Curve A $(-\cdot-)$, curve $\mathrm{B}(\cdots)$, and curve $\mathrm{C}(-\cdot-\cdot)$, respectively represent the contribution of backbone, side-chain and mixed modes to the heat capacity in $\alpha$ poly(L-valine). Curve D (-) shows sum of theoretical contributions. Experimental points are shown by

indicates that in the $\alpha$ helical conformation modes are less dispersive. This may be because the backbone is more flexible in the helical conformation and backbone modes are more sensitive to the intrachain coupling.

The contribution to heat capacity from the intramolecular interactions which give rise to lattice modes is bound to be appreciable because they also lie in the low frequency region. For this the calculations of dispersion curves for a three dimensional unit cell are 
necessary which is a difficult job. Interchain modes involving hindered translatory and rotatory motion will appear and the total number of modes will depend on the contents of the unit cell. Apart from the large dimensionality of the problem, it would bring in an enormous number of interactions and make the problem somewhat intractable. The interchain interactions are generally of the same order of magnitude as the weaker intrachain interactions. They can affect the force constants and depending on the crystal symmetry lead to crystal field splittings at the zone centre and zone boundary but the dominant assignments are not disturbed. Thus in-spite-of these limitations, the present work provides a good starting point for further basic studies on the thermodynamic behavior of polypeptides and proteins.

Acknowledgements. We are very much thankful to Prof. Takuya Yamashita, Faculty of Pharmaceutical Sciences, Tokushima University, Japan; for providing us the spectra of $\alpha$ poly(L-valine). Financial assistance to V.D.G. from the C.S.I.R. under Emeritus Scientist scheme is also gratefully acknowledged.

\section{REFERENCES}

1. L. Burman, P. Tandon, V. D. Gupta, and S. Srivastava, Polym.
J., 27, 481 (1995)

2. E. R. Blout, C. de Loze, S. M. Bloom, and G. D. Fasman, J. Am. Chem. Soc., 82, 3787 (1960).

3. S. M. Bloom, G. D. Fasman, C. de Loze, and E. R. Bloom, J. Am. Chem. Soc., 84, 484 (1962).

4. D. B. Fraser, B. S. Harrap, T. P. Macree, F. H. C. Stewart, and E. Suzuki, J. Mol. Biol., 12, 482 (1965).

5. G. D. Fasman, "Poly $(\alpha$-amino acid)s," Marcel Dekker Inc., New York, N.Y., 1967.

6. T. Ooi, R. A. Sutt, G. Vanderkooi, and H. A. Scheraga, J. Chem. Phys., 46, 4410 (1967).

7. R. F. Epand and H. A. Scheraga, Biopolymers, 6, 1551 (1968).

8. S. Yamashita and T. Yamashita, Proc. Natl. Acad. Sci. U.S.A., 72, 941 (1975).

9. G. D. Fasman, K. Itoh, C. S. Liu, and R. C. Lord, Biopolymer, 17, 125 (1978).

10. E. B. Wilson, J. C. Decuis, and P. C. Cross, "Molecular Vibrations: The Theory of Infrared and Raman Vibrational Spectra," Dower Publication, New York, N.Y., 1980.

11. P. W. Higgs, Proc. R. Soc., (London), Ser A, 472 (1953).

12. R. Pan, M. Verma-Nair, and B. Wunderlich, J. Therm. Anal., 35, 955 (1989).

13. M. V. Krishnan and V. D. Gupta, Chem. Phys. Lett., 6, 231 (1970).

14. J. L. Koenig and P. G. Sutton, Biopolymers, 10, 89 (1971).

15. P. K. Sengupta and S. Krimm, Biopolymers, 24, 1479 (1985).

16. S. Krimm and J. Bandekar, J. Adv. Protein Chem., 38, 181 (1986).

17. D. I. Bower and W. F. Maddams, "The Vibrational Spectroscopy of Polymers," Cambridge University Press, Cambridge, 1989, pp. $154-156$.

18. M. J. Hannon, F. J. Boerio, and J. L. Koenig, J. Chem. Phys., 50, 2829 (1969).

19. T. H. Benzinger, Nature, 229, 100 (1971). 